Supporting Information for

\title{
Ionic Strength-Controlled Mn (Hydr)Oxide Nanoparticle Nucleation on Quartz: Effect of Aqueous $\mathrm{Mn}(\mathrm{OH})_{2}$
}

\author{
Haesung Jung ${ }^{1}$ and Young-Shin Jun ${ }^{1}, *$ \\ ${ }^{1}$ Department of Energy, Environmental and Chemical Engineering, \\ Washington University, St. Louis, MO 63130
}

Address: One Brookings Drive, Campus Box 1180

E-mail:ysjun@seas.wustl.edu

Phone: (314)935-4539

Fax: (314)935-7211

http:/lencl.engineering.wustl.edu/

Submitted: June 2015

Revised: December 2015

Environmental Science and Technology

*To Whom Correspondence Should be Addressed

\section{Summary}

Thirty seven pages, including experimental and analytical descriptions and 7 Tables and 15 Figures. 


\section{S1. Preparation of quartz substrates}

Before the reaction, each quartz substrate was cleaned in a mixed solution of concentrated sulfuric acid and an oxidizing agent, Nochromix ${ }^{\circledR}$, for 1 day to remove organic matter, and was sonicated in acetone, ethanol, and isopropanol, for $15 \mathrm{~min}$ and then rinsed three times with ultrapure deionized water $\left(18.2 \mathrm{M} \Omega\right.$ resistivity). ${ }^{1-4}$ Until the substrates were used, they were stored in ultrapure deionized water. The cleaned substrates were imaged using AFM, as shown in Figure $\mathrm{S} 1$, to make sure that they were cleaned. The typical rms roughness of the cleaned quartz is about 2.0 $\AA$. Just before the cleaned substrate was inserted into the batch reactor, the substrate was dried by high purity nitrogen gas to remove the DI water.

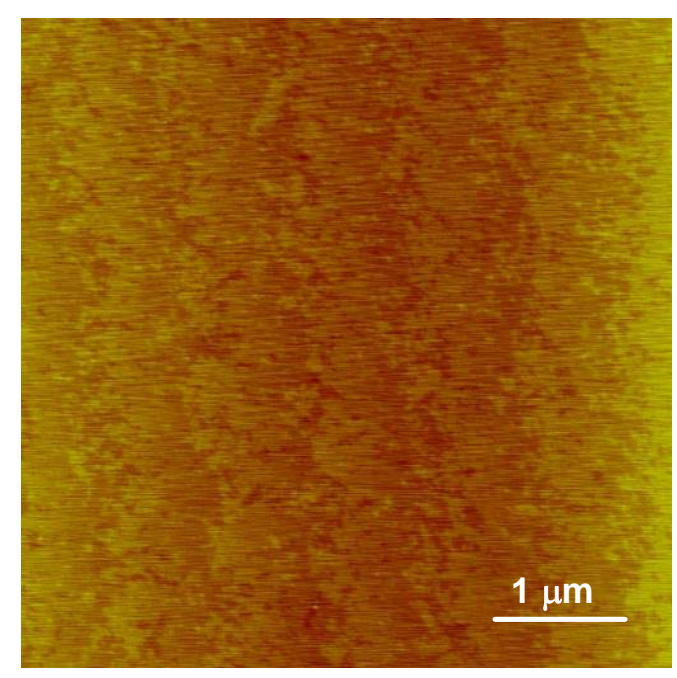

Figure S1. Clean (10 $\overline{1} 0)$ surface of quartz by AFM measurement. The AFM image size is $5 \mu \mathrm{m} \times$ $5 \mu \mathrm{m}$. The typical rms roughness of the cleaned quartz is about $2.0 \AA$.

\section{S2. AFM tapping mode information}

AFM probe tips were made of $0.01-0.025 \Omega \cdot \mathrm{cm}$ Antimony (n) doped Si (Model: RTESP, MPP-11100-10, Bruker). Cantilevers $125 \mu \mathrm{m}$ long and, $35 \mu \mathrm{m}$ wide. The drive frequency was 300 $\mathrm{kHz}$, and the spring constant was $40 \mathrm{~N} / \mathrm{m}$. The vertical information of particles was used if they 
were spherical and smaller than 30 to $40 \mathrm{~nm}$ in the lateral dimension because AFM is not then, due to tip artifacts. In situ fluid cell AFM experiments were initially tested, but the fragile nature of newly formed particles resulted in significant artifacts by AFM tips. Drying samples may decrease particle size by dehydration. However, the process does not affect trends in size, morphology, and concentration of particles. ${ }^{4}$ AFM images were analyzed using Nanoscope 7.20 software provided by Veeco.

\section{S3. Inductively coupled plasma-optical emission spectroscopy measurement}

All reactions were conducted in the absence of quartz substrate. After reactions, the samples were centrifuged at $11,000 \mathrm{rpm}$ for $5 \mathrm{~min}$. Then, $5 \mathrm{ml}$ of the supernatant solution was filtered using a $0.2 \mu \mathrm{m}$ polypropylene membrane and acidified using $5 \mathrm{ml}$ of $2 \% \mathrm{HNO}_{3}$ before ICP-OES measurements. We assumed that aqueous $\mathrm{Mn}$ concentrations did not include any significant $\mathrm{Mn}^{3+}$ aqueous species or $\mathrm{Mn}(\mathrm{III})$ and $\mathrm{Mn}$ (II) (hydr)oxide nanoparticles after centrifugation and filtration. This assumption is reasonable because $\mathrm{Mn}^{3+}$ is not soluble unless there are organic compounds present. ${ }^{5,6}$ We pretested and optimized the centrifugation and filtration processes to make sure that all the Mn (hydr)oxide nanoparticles can be removed.

\section{S4. Small angle X-ray scattering (SAXS) 2-D image analyses}

SAXS measurement, $14 \mathrm{keV}$ was utilized to achieve good transmission through a Kapton ${ }^{\circledR}$ window. A sample to detector distance of two meters $\left(0.0085 \AA^{-1}<\right.$ scattering vector $\left.q<0.276 \AA^{-1}\right)$ was used. To avoid any X-ray beam interaction with Mn (hydr)oxide formation, each measurement of the varied elapsed times was done using newly prepared solutions and a 10 second beam exposure time. For the SAXS data analyses of $2 \mathrm{D}$ images, the solution scattering before starting the reaction was used for background subtraction. For each SAXS image, the intensities were 
azimuthally averaged over the $2 \mathrm{D}$ image at each scattering vector $\left(q\right.$, unit: $\left.\AA^{-1}\right)$. For further analysis of the information from SAXS data, the invariant, $Q$, is calculated by

$$
Q=\int I(q) q^{2} d q,
$$

where $I(q)$ is the resulting scattering intensity, and $q$ is the range of magnitude of the scattering vector. The calculated $Q$ is proportional to the total particle volume, which is subsequently proportional to the total particle number. Data processing was conducted with Igor Pro (v 6.22A, WaveMetrics, Inc., Oregon). More detailed descriptions can be found in our previous studies. ${ }^{1,3,4}$

\section{S5. Electrophoretic mobility measurements.}

A zetasizer (Nano ZS, Malvern Instruments Ltd.) tested the electrophoretic mobility of homogeneously and heterogeneously nucleated particles. To measure the zeta potential of the quartz without Mn (hydr)oxide formation, the quartz powders, which was expected to have similar

electrostatic properties as y-cut single face quartz, ${ }^{7}$ were measured at our experimental conditions because of the technical difficulty in measuring zeta potentials from single crystal quartz surface. $0.5 \mathrm{~g}$ of ground quartz powder and $2 \mathrm{ml}$ of each reaction solution $(1 \mathrm{mM}, 10 \mathrm{mM}$ or $100 \mathrm{mM}$ $\mathrm{NaNO}_{3}$ without $\mathrm{Mn}\left(\mathrm{NO}_{3}\right)_{2}$ at a $\mathrm{pH}$ of $10.1 \pm 0.1$, adjusted using $\mathrm{NaOH}$ ) were mixed and allowed to settle for $10 \mathrm{~min}$. Solution from the upper region, which contained small suspended quartz power particles, that provide stable zeta potential signals, was analyzed. There is a caveat that the absolute values of the zeta potential measured with quartz powder can differ from that of the single crystal quartz surface. However, the zeta potential trend should be similar.

\section{S6. Sample preparation for Mn (hydr)oxide phase identification}

To prepare samples for ex situ phase identification of nucleated particles on quartz substrates (heterogeneous nucleation), $0.05 \mathrm{~g}$ of ground quartz powder for $\mathrm{X}$-ray photoelectron 
spectroscopy (XPS, PHI 5000 VersaProbe II, Ulvac-PHI, Inc., Japan) was reacted in $2 \mathrm{ml}$ of each reaction solution $\left(1 \mathrm{mM}\right.$ and $100 \mathrm{mM} \mathrm{NaNO}_{3}$ with $0.1 \mathrm{mM} \mathrm{Mn}\left(\mathrm{NO}_{3}\right)_{2}$, at a $\mathrm{pH}$ of $10.1 \pm 0.05$ adjusted using $\mathrm{NaOH}$ ) during $1 \mathrm{hr}$. To prepare ex situ samples of nucleated particles in the solutions (homogeneous nucleation), $2 \mathrm{~L}$ volumes of each reaction condition were prepared and reacted for $2 \mathrm{hr}$. After the end of reaction time, the solutions were divided for convenience and centrifuged four times at $5000 \mathrm{rpm}$ for 15 minutes. After each centrifugation, the supernatant was pipetted off and discarded, and the precipitate was re-suspended in DI water to remove salt. The prepared samples were deposited either on a zero X-ray diffraction substrate (MTI Corporation) for HRXRD or on a glass substrate for Raman spectroscopy. The analyses of HRXRD (Bruker D8 ADVANCE X-ray diffractometer with $\mathrm{Cu}-\mathrm{K} \alpha$ radiation $(\lambda=1.5418 \AA)$ ) and Raman spectroscopy (Renishaw inVia) were performed after 1 day of drying. 
S7. Relationship between the terms of interfacial energy and the structural match with a substrate, and the CNT calculation procedure in our experimental system

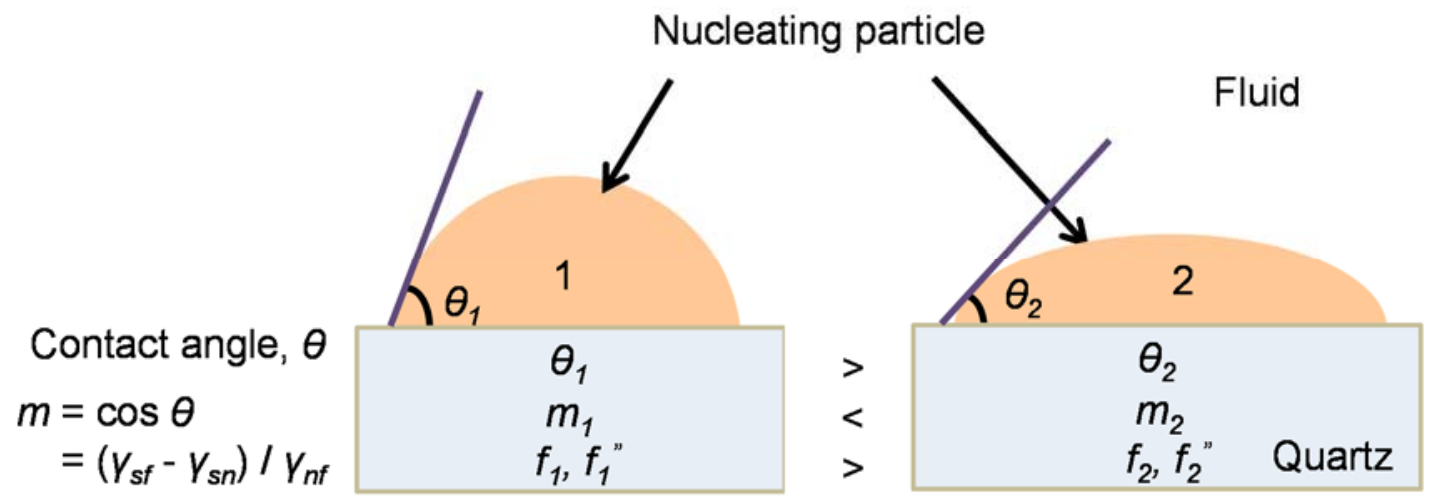

Figure S2. Schematic of nucleation particles on a quartz substrate when they have different structural matches with the substrate. Particle 1 has a higher contact angle than particle 2 . Therefore, $m_{2}\left(\cos \theta_{2}\right)$ is bigger than $m_{1}\left(\cos \theta_{1}\right)$.

To suggest the possible mechanism of observed nucleation behavior on a quartz substrate, the structural match at the interface between the nucleating particle and substrate can be calculated by utilizing CNT. CNT has been applied to explain heterogeneous nucleation behaviors. Specifically, CNT using a continuum concept of structural matches has been previously used to provide a physical basis for explaining the heterogeneous of $\mathrm{CaCO}_{3}$, ice, and organic crystals on a pre-existing substrate under varied supersaturation conditions. ${ }^{8-10}$ The equations for the calculation are

$$
\begin{aligned}
& J=J_{0} f^{\prime \prime}(m, x) f(m, x)^{1 / 2} \exp \left[-\frac{16 \pi \gamma_{n f}{ }^{3} \Omega^{2}}{3 k T[k T \ln (\sigma)]^{2}} f(m, x)\right], \\
& m=\cos \theta=\left(\gamma_{s f}-\gamma_{s n}\right) / \gamma_{n f},
\end{aligned}
$$




$$
\begin{aligned}
& f(m, x)=\frac{1}{2}+\frac{1}{2}\left(\frac{1-m x}{w}\right)^{3}+\frac{1}{2} x^{3}\left[2-3\left(\frac{1-m x}{w}\right)+\left(\frac{1-m x}{w}\right)^{3}\right]+\frac{3}{2} x^{3}\left(\frac{1-m x}{w}-1\right), \\
& f^{\prime \prime}(m, x)=\frac{1+(1-x m) / w}{2}, \\
& w=\left(1+x^{2}-2 x m\right)^{1 / 2}, \text { and } \\
& \tau=1 / J=\frac{1}{J_{0} f^{\prime \prime}(m, x) f(m, x)^{1 / 2} \exp \left[-\frac{16 \pi \gamma_{n f}{ }^{3} \Omega^{2}}{3 k T[k T \ln (\sigma)]^{2}} f(m, x)\right]} .
\end{aligned}
$$

Here, $J$ is the nucleation rate, $J_{0}$ is the kinetic constant, $\gamma_{n f}$ is the interfacial energy $\left(\mathrm{J} / \mathrm{m}^{2}\right)$ between the nucleating particle and fluid, $k$ is the Boltzmann constant $\left(1.38 \times 10^{-23} \mathrm{~J} / \mathrm{K}\right), T$ is the temperature, $\Omega$ is the volume of growth unit $\left(\mathrm{cm}^{3} /\right.$ molecule $), \tau$ is the induction time of nucleation, $f$ and $f$ " are the interfacial correlation function describing the influence of substrates on the nucleation barrier. Further, $w$ is the dimensionless distance between the center of the substrate and the center of the nucleating particle divided by the critical radius, $R^{s}$ is the average radius of substrates of a spherical shape, $r_{c}$ is the critical radius, and $x$ is the relative size of foreign particles $\left(R^{s} / r_{c}\right) . m$ is a parameter depending on the interaction and structural matching between the nucleating particle and the substrate. It is related to the interfacial energy between two different phases by,

$$
m=\cos \theta=\left(\gamma_{s f}-\gamma_{s n}\right) / \gamma_{n f},
$$

where $\gamma_{s f}$ is the interfacial energy between the substrate and fluid, and $\gamma_{s n}$ is the interfacial energy between the substrate and nucleating particle. At each supersaturation ratio, heterogeneous nucleation occurs fastest at a certain contact angle, $\theta$, between the nucleating particle and substrate. If we express the integrated term of interfacial energies as $m$ in equation (S8), then $m$ represents the contact angle between the substrate and nucleating particle as shown in Figure S2. The concept of structural match arises in classical nucleation theory from the derivation of the free energy of 
formation for heterogeneous nuclei. A structure match can be also experimentally determined if the lattice spacing of a film and substrate at their interfacial structure can be resolved. For heterogeneous nucleation, the free energy of formation is given by ${ }^{8,11}$

$$
\begin{aligned}
& \Delta G=\Delta G_{v} V_{n}+\gamma_{n f} S_{n f}+\left(\gamma_{s n}-\gamma_{s f}\right) S_{s n}, \\
& S_{n f}=2 \pi r_{c}^{2}(1-(x-m) / w), \\
& S_{s n}=2 \pi R^{s^{2}}(1+(1-m x) / w), \text { and }
\end{aligned}
$$

$$
\begin{aligned}
V_{n}= & \frac{1}{3} \pi r^{3}\left(2-3((x-m) / w)+((x-m) / w)^{3}\right) \\
& -\frac{1}{3} \pi R^{s^{3}}\left(2-3((1-m x) / w)+\left(2-3((1-m x) / w)^{3}\right.\right.
\end{aligned} .
$$

Here, $\Delta G$ is the free energy of formation, $\Delta G_{v}$ is the free energy difference per unit volume of nucleating particle, $V_{n}$ is the volume of the nucleating particle on the substrate, and $S_{n f}$ and $S_{s n}$ are the surface areas of the interface between the nucleating particle and fluid, and between the substrate and nucleating particles, respectively.

The critical free energy of nucleation is required to satisfy

$$
\partial \Delta G^{*} / \partial r=0 .
$$

The critical radius is obtained from the nucleation equation,

$$
r^{*}=-2 \gamma_{n f} / \Delta G_{v} .
$$

By substituting the expressions from equation (S10), (S11), (S12), and (S14) into equation (S9), the free energy of formation of a critical nucleus on a substrate is 


$$
\Delta G^{*}=\frac{16 \pi \gamma_{n f}^{3} \Omega^{2}}{3 k T[k T \ln (\sigma)]^{2}} f(m, x) .
$$

As shown in equations (S9) to (S15), $f$ is derived by considering the free energy of formation of a critical nucleus, and $f$ " is derived for the surface of the nucleating particle on the substrate to consider the frequency of collision with other nucleating particles. Because both $f$ and $f$ " are derived from the surface area and volume of nucleated particle on the substrate, ${ }^{11}$ these are controlled by $m$. When $m \rightarrow 1$, which means that the contact angle goes to zero, the nucleated particle has a good structural match with the substrate, and $f$ and $f$ " go to zero. On the other hand, when $m \rightarrow-1$, and $x=0, f$ and $f$ " become 1 , and equation (S2) describes the homogeneous nucleation rate.

For calculations, we assumed that $x$ is 1000 to describe heterogeneous nucleation on flat substrate. ${ }^{8}$ The $m$ values showed the obtained points from this iterating calculation to find the interaction condition between the nucleating particle and substrate under each saturation condition in Figure 5. $f$ and $f$ "' are calculated from the $m$ values.

Using the initial activities of $\mathrm{OH}^{-}(\mathrm{aq})$ and $\mathrm{Mn}^{2+}$ (aq), the supersaturation ratios were calculated with respect to pyrochroite based on phase identification. Because our system did not have a Mn (III, IV) oxide formation, we can rule out the possibility of a polymerized cluster of solid Mn ((III)/IV) oxide as an initial precipitate. ${ }^{12}$ Reports by Morgan regarding Mn oxidation kinetics discussed that, in a supersaturated condition of $\mathrm{Mn}(\mathrm{OH})_{2}(\mathrm{~s}), \mathrm{Mn}(\mathrm{OH})_{2}(\mathrm{~s})$ is the initial precipitate. ${ }^{12,13}$ The oxidation of $\mathrm{Mn}(\mathrm{OH})_{2}(\mathrm{~s})$ is very rapid, and leads to $\mathrm{Mn}_{3} \mathrm{O}_{4}$ phase. ${ }^{12}$ At an undersaturated condition, $\mathrm{MnOOH}$ was observed as initial precipitate. ${ }^{12}$ At both supersaturated and undersaturated conditions, $\mathrm{Mn}$ oxidation happens from $\mathrm{Mn}(\mathrm{OH})_{2}$ (s) and $\mathrm{Mn}(\mathrm{OH})_{2}(\mathrm{aq})$, respectively. This suggests that the hydroxide ions favor oxidation of $\mathrm{Mn}^{2+} \cdot{ }^{14} \mathrm{Also}$, studies by Hem 
reported that the polymerized cluster, the precursor of $\mathrm{Mn}(\mathrm{OH})_{2}(\mathrm{~s})$, is the initial precipitate in the supersaturated condition of $\mathrm{Mn}(\mathrm{OH})_{2}$ (s). ${ }^{15,16}$ Then, the precursor is transformed to $\beta-\mathrm{MnOOH}$ or $\mathrm{Mn}_{3} \mathrm{O}_{4}$ at lower temperature and higher temperature than $10^{\circ} \mathrm{C}$, respectively. Because $\beta-\mathrm{MnOOH}$ has a similar structure with pyrochroite, minimal disruption is required for a loss of protons to maintain charge balance. ${ }^{15,16}$ However, the structure of $\mathrm{Mn}_{3} \mathrm{O}_{4}$ is different and requires a greater degree of disruption (higher energy barrier) due to a need for ejection of surplus water molecules. Thus, Hem's studies reported that the rate of formation of $\mathrm{Mn}_{3} \mathrm{O}_{4}$ from polymerized pyrochroite would be more strongly temperature dependent than that of $\beta-\mathrm{MnOOH}$, and the latter turns out to be kinetically favored below about $10{ }^{\circ} \mathrm{C} .{ }^{15}, 16$ Therefore, we proposed that $\mathrm{Mn}$ (II) hydroxide polymer is as initiator of the Mn (hydr)oxide formation in our supersaturated condition with regard to $\mathrm{Mn}(\mathrm{OH})_{2}$ (s)." For pyrochroite, the calculated supersaturation ratios are respectively 9.2 and 6.8 for $1 \mathrm{mM}$ and $100 \mathrm{mM}$ IS, based on a $K_{s p}$ of $10^{-15.2} \cdot{ }^{17}$ Because there is no study on the interfacial energy of pyrochroite, we assumed its interfacial energy to be $0.05 \mathrm{~J} / \mathrm{m}^{2}$. Previous studies suggested that the higher oxidation state is favored by the higher interfacial energy from oxidation reduction phase equilibrium at nanoscale. ${ }^{18} \mathrm{Mn}(\mathrm{OH})_{2}$ (s) can have a lower interfacial energy than hydrated $\mathrm{Mn}_{3} \mathrm{O}_{4}, 0.96 \mathrm{~J} / \mathrm{m}^{2} .{ }^{18} \mathrm{CNT}$ calculation showed film growth $(m=\sim 1)$ when an interfacial energy higher than $0.20 \mathrm{~J} / \mathrm{m}^{2}$ was used for the calculation. Therefore, to have the formation of heterogeneously nucleated particle as showed in our AFM images, an interfacial energy smaller than $0.20 \mathrm{~J} / \mathrm{m}^{2}$ is required. Also, $\mathrm{Mn}(\mathrm{OH})_{2}$ (s) has a similar structure to $\mathrm{Fe}(\mathrm{OH})_{2}(\mathrm{~s})$, and the interfacial energy of $\mathrm{Fe}(\mathrm{OH})_{2}$ (s) is reported as $0.05 \mathrm{~J} / \mathrm{m}^{2} .{ }^{19}$ Hence, assuming the interfacial energy of $\mathrm{Mn}(\mathrm{OH})_{2}$ (s) as $0.05 \mathrm{~J} / \mathrm{m}^{2}$ is reasonable in calculating the nucleation rate based on the oxidationreduction phase equilibrium at nanoscale, the CNT calculation, and the structural similarity with $\mathrm{Fe}(\mathrm{OH})_{2}(\mathrm{~s}){ }^{18-20}$ 


\section{S8. The discussion for the $\mathrm{pH}$ and dissolved oxygen conditions.}

Under controlled $\mathrm{pH}$ and IS conditions, $\mathrm{pH}$ changes were monitored with and without manganese to investigate how $\mathrm{pH}$ changes, and how manganese formation and oxidation affect the solution $\mathrm{pH}$ change over $1 \mathrm{hr}$. Because using a buffer solution can cause unknown effects on nucleation behavior (e.g., complexation and IS changes from the addition of buffer), an unbuffered experimental system was used in this study to investigate the effect of IS on the early nucleation and growth behavior of Mn (hydr)oxide. As shown in Figure S3, pH does not show decrease in open systems with stirring $( \pm 0.05)$. A much longer exposure of the reaction solution than $1 \mathrm{hr}$ will show a $\mathrm{pH}$ decrease by carbon dioxide dissolution. However, in $1 \mathrm{hr}$ reaction, carbon dioxide dissolution did not significantly decrease on $\mathrm{pH}$. With $\mathrm{Mn}^{2+}$ addition, $\mathrm{pH}$ decreased, and the decrease showed a difference under varied IS conditions. This suggests that the decrease of $\mathrm{pH}$ is mostly attributed to $\mathrm{Mn}(\mathrm{OH})_{2}$ (s) formation or Mn oxidation. Dissolved oxygen concentrations at $1 \mathrm{mM}$ and $100 \mathrm{mM}$ did not show significant change during $1 \mathrm{hr}$ reaction either (Figure $\mathrm{S} 3 \mathrm{C}$ ). Therefore, the faster decrease of $\mathrm{pH}$ and $\mathrm{Mn}^{2+}$ concentration in solution and faster homogeneous nucleation at $1 \mathrm{mM}$ IS indicates a higher supersaturation of $\mathrm{Mn}(\mathrm{OH})_{2}$ (s) at $1 \mathrm{mM}$ IS than that at $100 \mathrm{mM}$ IS. 

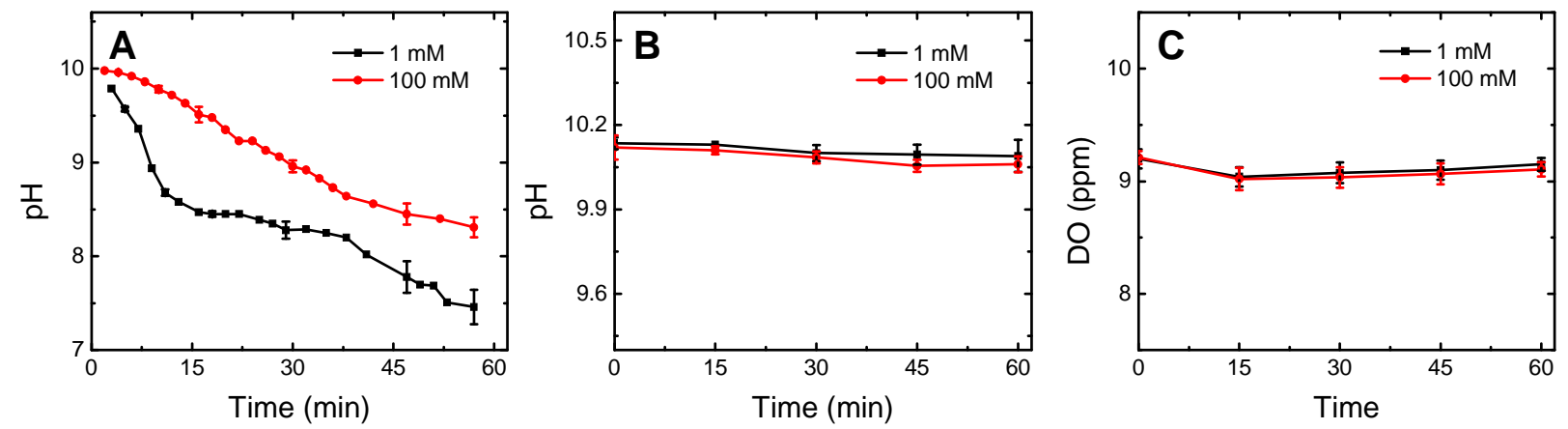

Figure S3. (A) pH changes during $1 \mathrm{hr}$ reaction in the existence of manganese. (B) Consistent $\mathrm{pH}$ values during $1 \mathrm{hr}$ without manganese insertion. (C) The concentration of dissolved oxygen during $1 \mathrm{hr}$ reaction, which are relatively stable in the absence of Mn ions. 


\section{S9. Thermodynamic calculations to check the impacts of Mn-bicarbonate and Mn- carbonate complexation on the supersaturation of $\mathrm{Mn}(\mathrm{OH})_{2}(\mathrm{~s})$.}

Our systems were saturated with respect to pyrochroite $\left(\mathrm{Mn}(\mathrm{OH})_{2}(\mathrm{~s})\right)$. In this study, we focused on the $\mathrm{Mn}(\mathrm{OH})_{2}$ (s) supersaturation changes by varying IS, and on the effects of IS on the heterogeneous nucleation of $\mathrm{Mn}(\mathrm{OH})_{2}(\mathrm{~s})$ and $\mathrm{Mn}_{3} \mathrm{O}_{4}(\mathrm{~s})$. To check the effect of bicarbonate and carbonate complexation with $\mathrm{Mn}^{2+}$ on $\mathrm{Mn}(\mathrm{OH})_{2}$ (s) supersaturation changes, thermodynamic calculation using Geochemist's Workbench Standard 8.0 (GWB 8.0) were conducted under the varied IS conditions (Table S2). Although bicarbonate and carbonate are strong complex-formers, and are affected by ionic strength, they exist at a much smaller concentration than $\mathrm{Mn}^{2+}$ (aq) based on our thermodynamic calculations (At $1 \mathrm{mM} \mathrm{IS,} \mathrm{the} \mathrm{concentrations} \mathrm{of} \mathrm{Mn-bicarbonate}$ $\left(\mathrm{MnHCO}_{3}{ }^{+}\right)$and $\mathrm{Mn}-$ carbonate $\left(\mathrm{MnCO}_{3}(\mathrm{aq})\right)$ complexes were $0.0002 \mathrm{mM}$ and $0.00004 \mathrm{mM}$, respectively. At $100 \mathrm{mM}$ IS, the concentrations of $\mathrm{Mn}$-bicarbonate $\left(\mathrm{MnHCO}_{3}{ }^{+}\right)$and $\mathrm{Mn}$-carbonate $\left(\mathrm{MnCO}_{3}(\mathrm{aq})\right)$ complexes were $0.0001 \mathrm{mM}$ and $0.00001 \mathrm{mM}$, respectively). These concentrations are much smaller than $\mathrm{Mn}^{2+}$ (aq) $(0.099 \mathrm{mM}$ and $0.093 \mathrm{mM}$ at $1 \mathrm{mM}$ IS and $100 \mathrm{mM}$ IS, respectively). Also, based on the $\mathrm{pH}$ measurement and $\mathrm{DO}$ measurement in Figure $\mathrm{S} 3$, we confirmed that our system's $\mathrm{pH}$ values were not significantly affected by $\mathrm{CO}_{2}$ dissolution. The smaller concentrations of Mn-carbonate related complexes compared to $\mathrm{Mn}^{2+}$ (aq) indicates that complexation with bicarbonate and carbonate does not significantly affect $\mathrm{Mn}(\mathrm{OH})_{2}$ (s) supersaturation. 

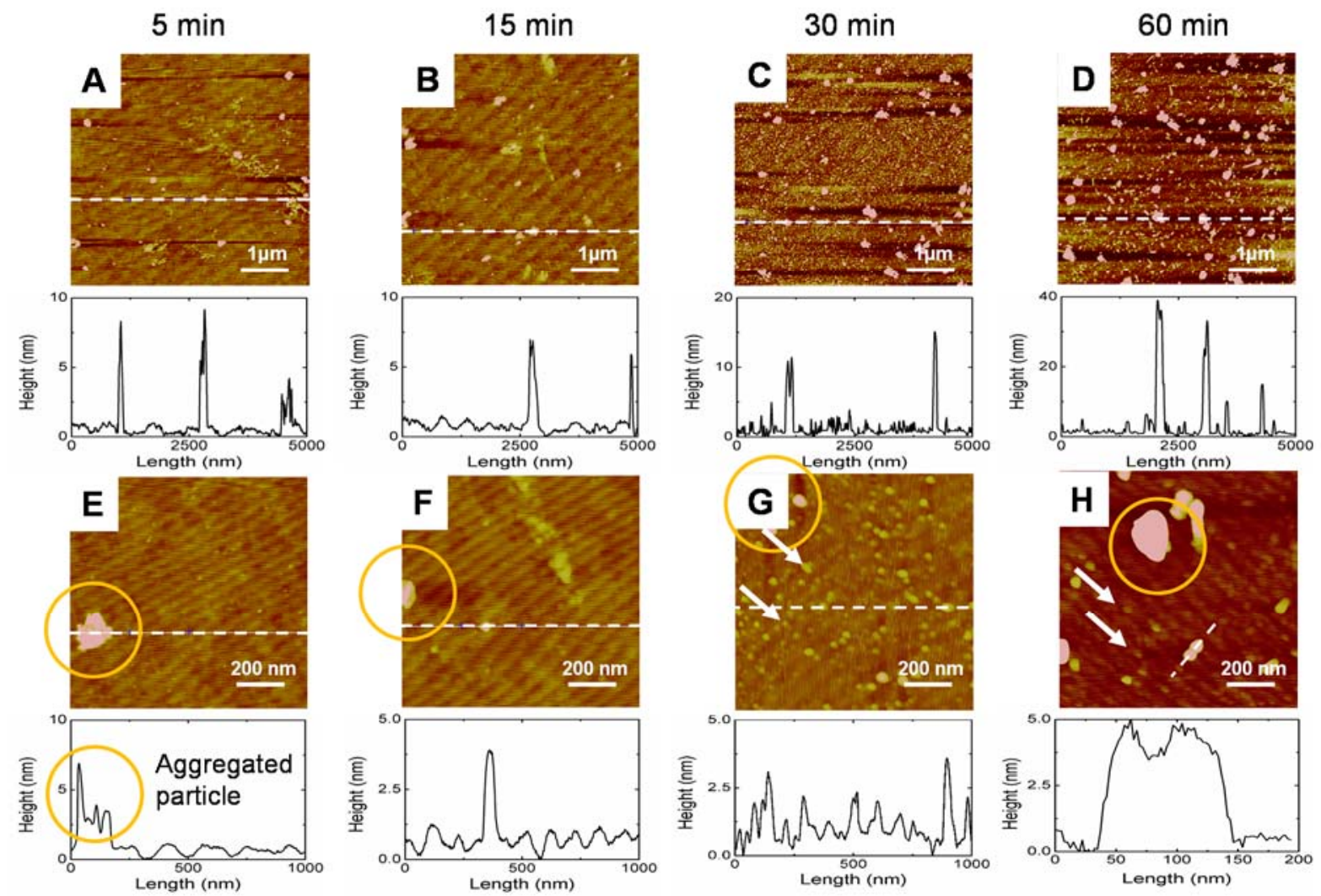

Figure S4. AFM height images of different elapsed times in $1 \mathrm{mM}$ IS: 5 min (A and E), 15 min (B and $\mathrm{F}), 30 \min (\mathrm{C}$ and $\mathrm{G})$ and $60 \min (\mathrm{D}$ and $\mathrm{H})$. At the early reaction times, large aggregated particles are observed, and small particles are made later. A $0.5 \mathrm{~nm}$ step width is shown in all images. The AFM image sizes of first row and second row are $5 \mu \mathrm{m} \times 5 \mu \mathrm{m}$ and $1 \mu \mathrm{m} \times 1 \mu \mathrm{m}$, respectively. 

quartz.
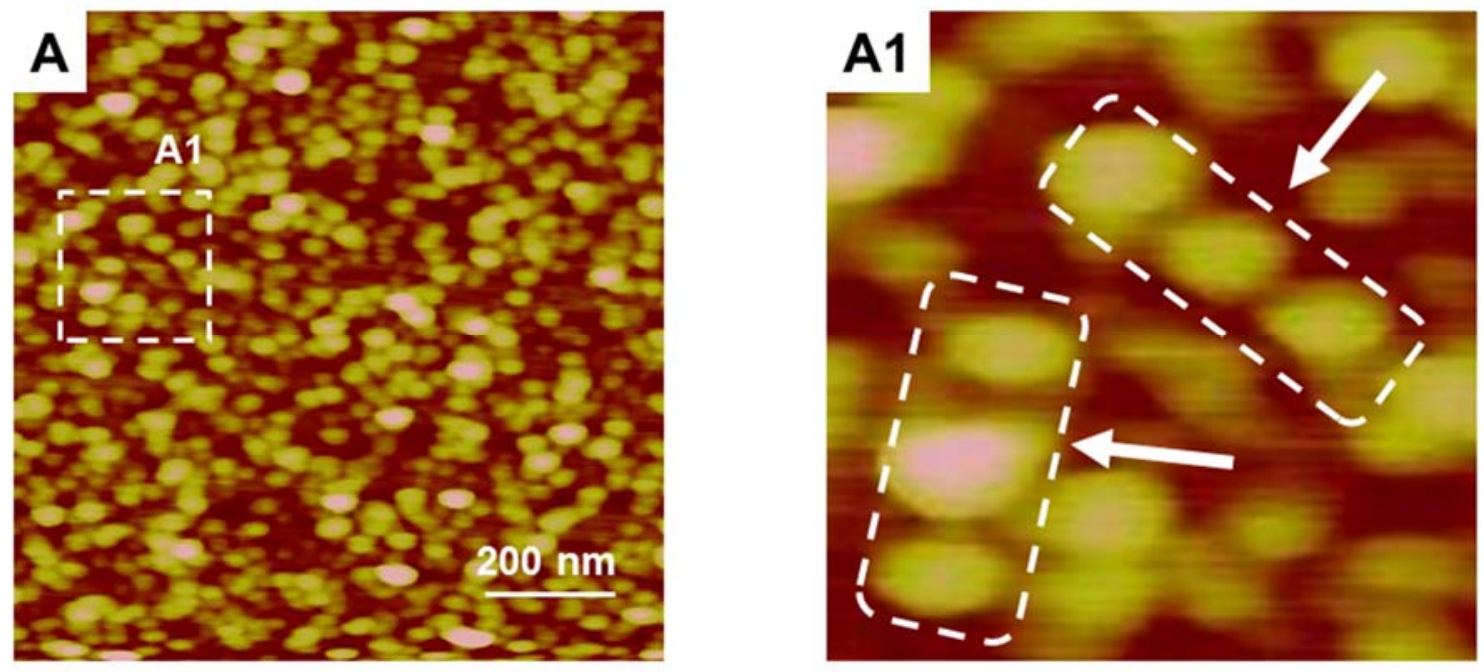

Figure S5. AFM height image from the $100 \mathrm{mM}$ IS system (A) at $15 \mathrm{~min}$, and (A1) zoomed-in image. Formation of heterogeneously nucleated particles on top of a heterogeneously nucleated particle on quartz. After the particles undergo growth, they have an aggregation with connecting points between two particles as shown, and become a rod-shaped assembly. 


\section{S12. Verification of the validity of the oriented attachment of rod-shaped aggregate in AFM}

image.

Figure S6, from the $100 \mathrm{mM}$ IS condition, shows the heights of rod-shaped particles lying parallel (Figure S6A1) and perpendicular (Figure S6B1) to the AFM scanning direction. Specifically, there is a rod-shaped particle aligned perpendicular to the AFM scanning direction (Figure S6B). The image in a perpendicular direction has similar valleys (B1) to those on the rodshaped particles in the parallel direction (Figure S6A1). The different scanning directions confirm that these valleys do not result from tip artifacts, but rather come from the attaching points of individual particles. The dimension of the longer axis of rod particles ranged from 150-250 nm, which is much larger than the dimension which is not affected by the $8 \mathrm{~nm}$ AFM tip radius.
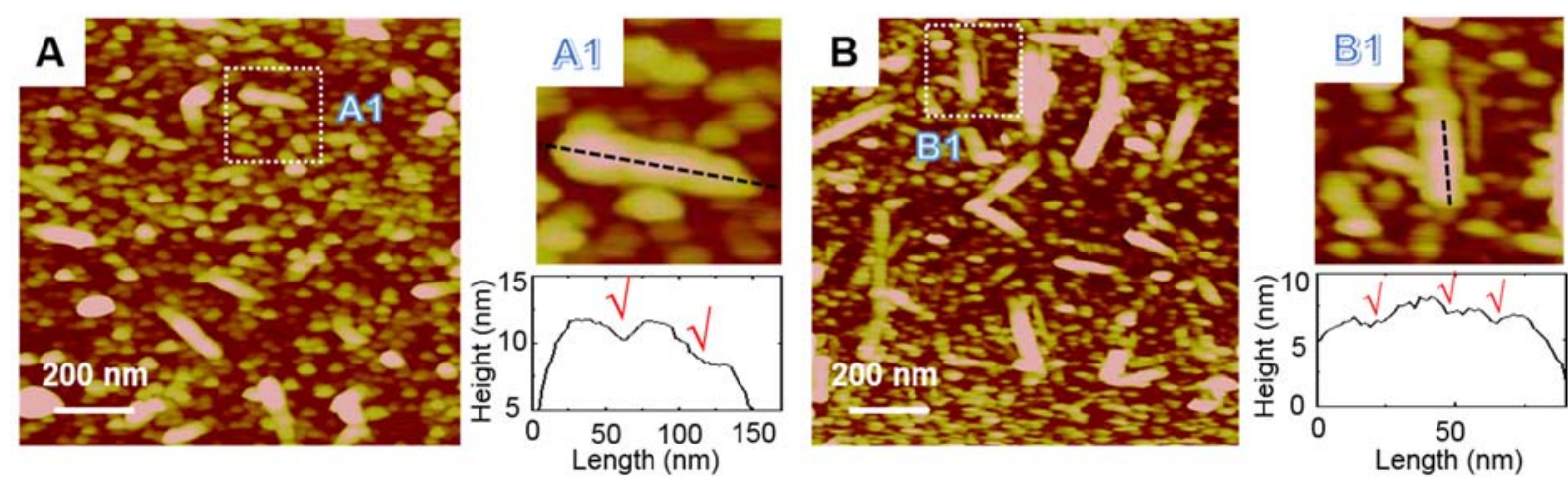

Figure S6. AFM height images with zoomed-in images in the $100 \mathrm{mM}$ IS condition. (A) and (B) were obtained from different positions. (A1) Rod-shaped particle aligned in parallel with the AFM scanning direction. (B1) Rod-shaped particle aligned perpendicular to the AFM scanning direction. 
S13. Comparison of aggregated particles between $1 \mathrm{mM}$ and $10 \mathrm{mM}$ IS systems
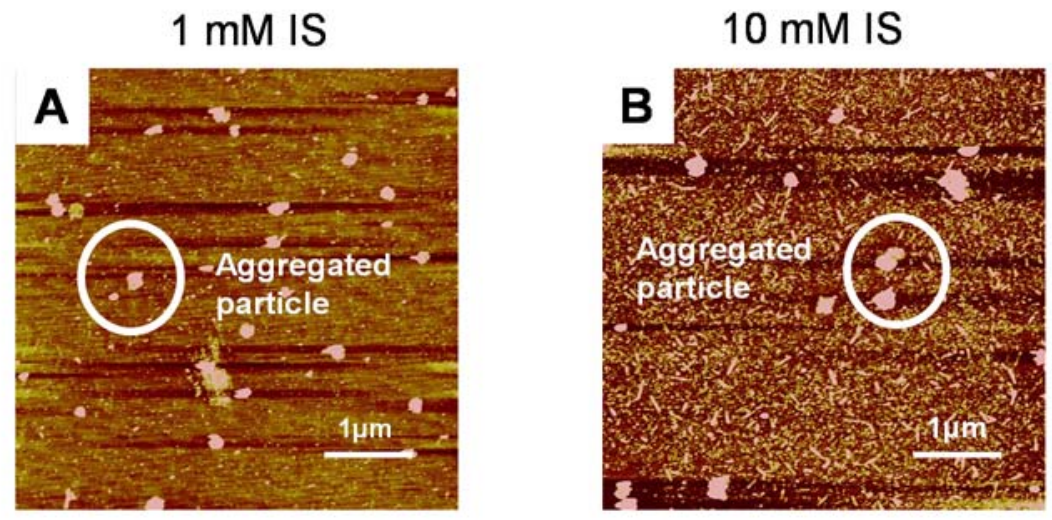

Figure S7. AFM height images for comparison of aggregated particles between $1 \mathrm{mM}$ IS (A) and $10 \mathrm{mM}$ IS (B). $1 \mathrm{mM}$ IS showed more round aggregated particles than $10 \mathrm{mM}$ IS. The AFM image size is $5 \mu \mathrm{m} \times 5 \mu \mathrm{m}$. 
S14. Phase identification of homogeneously nucleated Mn (hydr)oxide using Raman spectroscopy

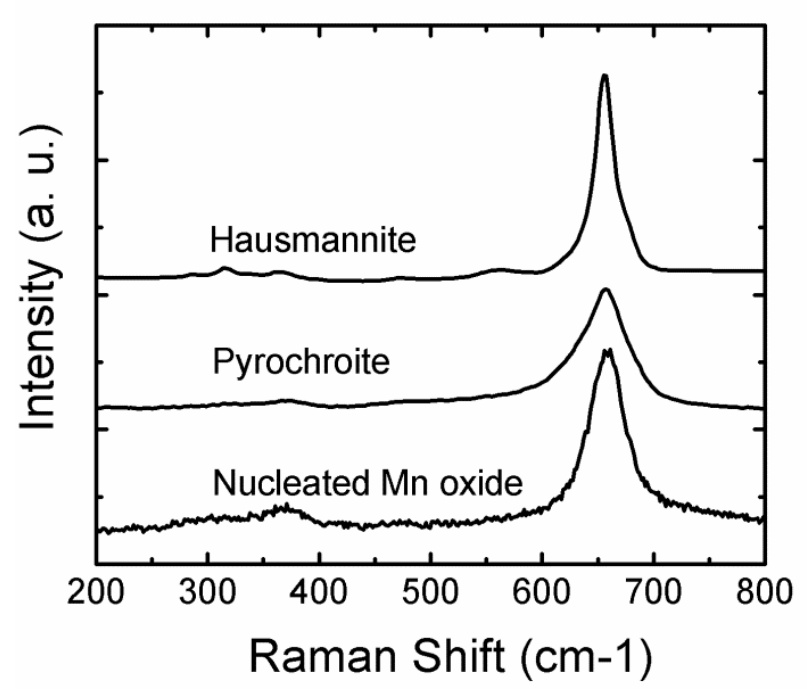

Figure S8. Raman spectra of homogeneously nucleated Mn (hydr)oxide particles. Raman bands of 310,357 , and $653 \mathrm{~cm}^{-1}$ indicated hausmannite and pyrochroite. However, pyrochroite cannot be distinguished from hausmannite. 
S15. Additional references of commercially obtained Mn(II) and Mn(III) minerals.
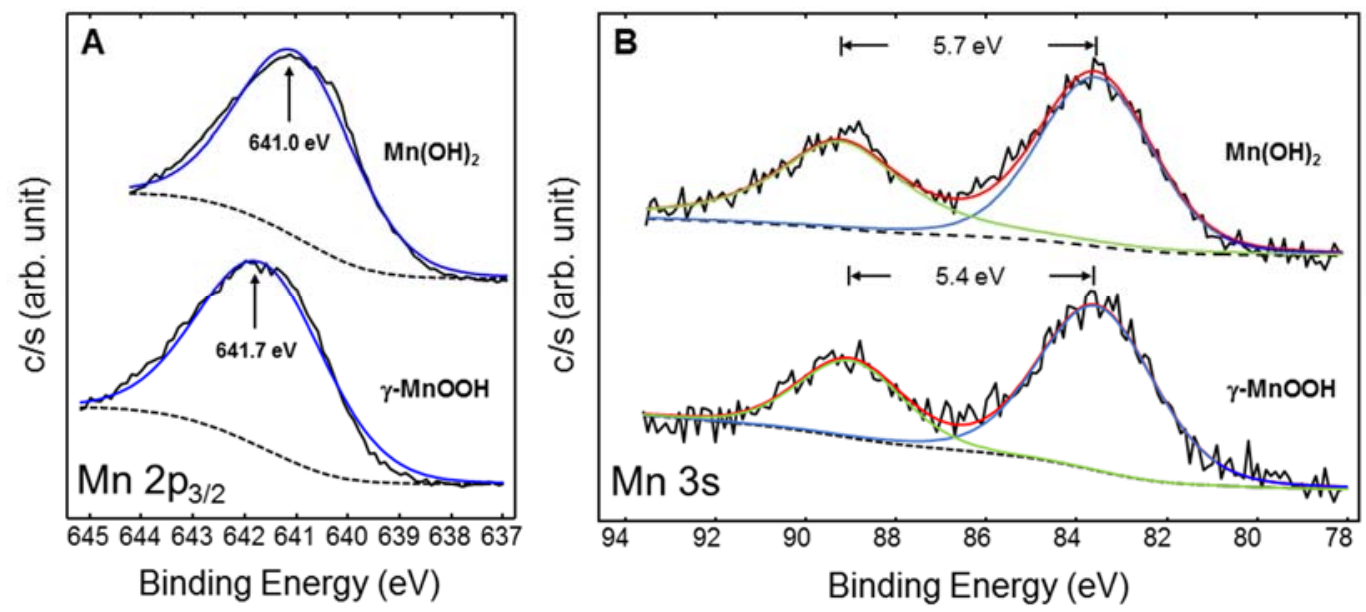

Figure S9. Reference XPS spectra of commercially obtained $\mathrm{Mn}(\mathrm{OH})_{2}$ (s) originating from the N'Chwaning II Mine, Northern Cape Province, South Africa (Mineralogical Research Co.) and $\gamma$ MnOOH originating from the Atikokan area, Ontario, Canada (Mineralogical Research Co.). (A) Mn 2p $3 / 2$ XPS spectra. (B) Mn 3s XPS spectra. 


\section{S16. The description of fitting results in Mn 2p/2 and Mn 3s XPS spectra.}

In Figure S10, the XPS spectra are compared with the Mn(II) only fitting and with the fitting which includes $\mathrm{Mn}(\mathrm{II})$ and $\mathrm{Mn}(\mathrm{III})$. The plots show that the spectra cannot be well-fitted using $\mathrm{Mn}(\mathrm{II})$ only: For both $1 \mathrm{mM}$ IS and $100 \mathrm{mM}$ IS, the fitting is over-estimated from the peak position at lower binding energy, and under-estimated at higher binding energies. When both the $\mathrm{Mn}$ (II) and $\mathrm{Mn}$ (III) oxidation states are used, the fitting is much better than for $\mathrm{Mn}$ (II) only.

Fitting with only $\mathrm{Mn}$ (II)

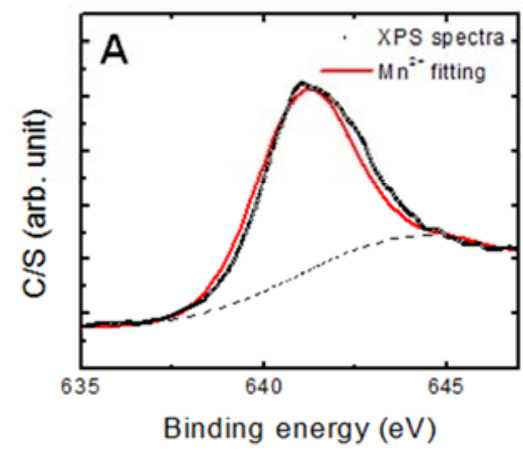

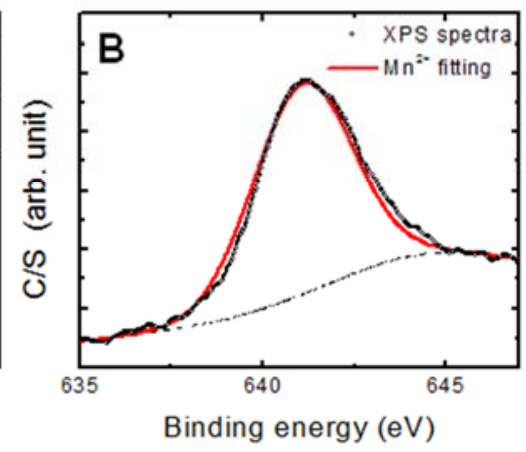

Figure S10. XPS spectra obtained from the heterogeneously nucleated particles on the quartz surface and the fitting line using Mn(II) only at (A) $1 \mathrm{mM}$ IS and (B) $100 \mathrm{mM}$ IS, and using (C) both $\mathrm{Mn}(\mathrm{II})$ and $\mathrm{Mn}(\mathrm{III})$.

To support the observed results from Mn $2 \mathrm{p}$ analysis, Mn 3s multiplet splitting was analyzed. The reference Mn 3s multiplet splitting values for $\mathrm{Mn}(\mathrm{II})$ and $\mathrm{Mn}(\mathrm{III})$ were considered to be $5.8 \mathrm{eV}$ and $5.2 \mathrm{eV}$, respectively, based on previous literature provided in Table $\mathrm{S} 3$. As shown in Figure S11, in aerobic conditions, smaller values $(5.5 \mathrm{eV}$ and $5.6 \mathrm{eV}$ at $1 \mathrm{mM}$ and $100 \mathrm{mM}$, respectively) of $\mathrm{Mn} 3 \mathrm{~s}$ muliplet splitting were observed than in anaerobic conditions (5.8 eV at both $1 \mathrm{mM}$ and $100 \mathrm{mM}$ IS). The analysis indicates the oxidation state of formed particles was 
$\mathrm{Mn}(\mathrm{II})$ in anaerobic condition. In aerobic condition, the energy values were in the middle of $\mathrm{Mn}$ (II) $(5.8 \mathrm{eV})$ and $\mathrm{Mn}(\mathrm{III})(5.2 \mathrm{eV})$. The energy values show that, in aerobic condition, the heterogeneously nucleated particles have both $\mathrm{Mn}(\mathrm{II})$ and $\mathrm{Mn}$ (III). The results are consistent with the shift analysis of the $\mathrm{Mn} 2 \mathrm{p}_{3 / 2}$ orbital spin.

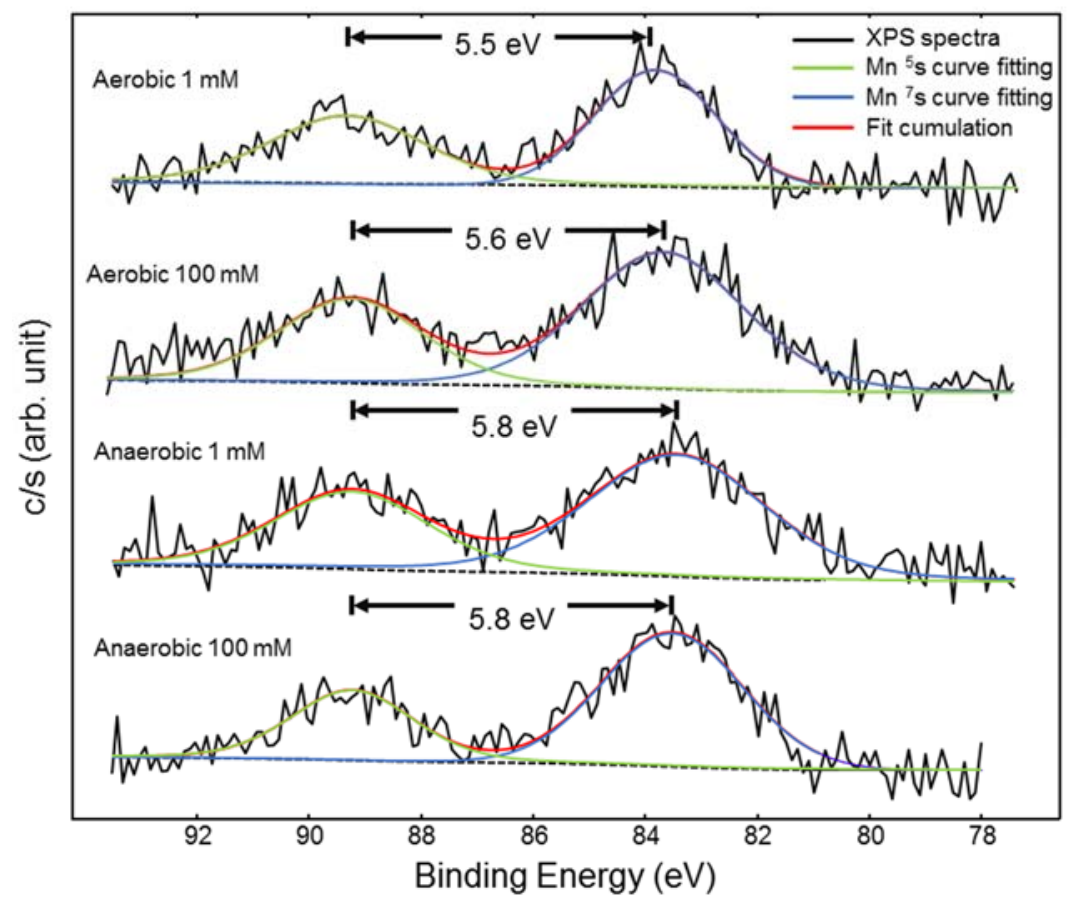

Figure S11. XPS spectra of Mn 3s photoelectron lines. The top two spectra were obtained from the aerobic condition in the varied IS systems. The bottom two spectra were obtained from the anaerobic condition in the varied IS systems. 


\section{S17. The fitting comparison for O1s photopeak of XPS spectra.}

In Figure S12, the O1s photopeaks of XPS spectra obtained from aerobic and anaerobic conditions were fitted by Gaussian-Lorentzian curve-fitting. From all O1s spectra, there were the strongest peak is at $532.3 \mathrm{eV}$ (blue line) $)^{21,22}$, which comes from the oxygen bonding in the quartz crystal. In aerobic conditions, there was a small peak at $530.1 \mathrm{eV}$ (green line) $)^{23,24}$, which is ascribed to lattice oxygen $\mathrm{O}^{2-}$ from $\mathrm{Mn}$ Oxide. The analysis of O1s spectra can help to understand the formation of Mn (hydr)oxide. However, as shown in Figure S12, because our experimental system has a quartz substrate, and the oxygen peak of the quartz has very strong intensities, we could not see any observable peaks of hydroxide and water-based oxygen.
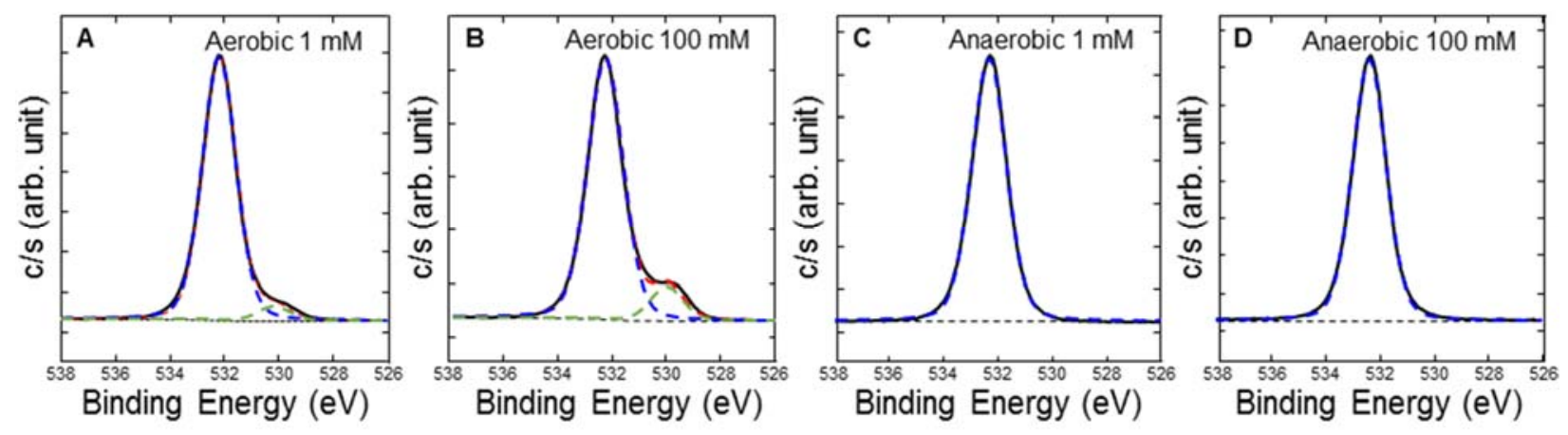

Figure S12. XPS O1s spectrum of heterogeneously nucleated Mn (hydr)oxide on the quartz substrate in (A) aerobic $1 \mathrm{mM}$, (B) aerobic $100 \mathrm{mM},(C)$ anaerobic $1 \mathrm{mM}$, and (D) anaerobic 100 mM IS. The black line represents the spectral data. The blue line and green line represent the $\mathrm{O} 1 \mathrm{~s}$ spectrum from quartz and Mn oxide, respectively. The horizontal black line represents the Shirley background. 


\section{S18. Identification of the mineral phases of the initial stage of heterogeneously nucleated Mn}

(hydr)oxide and particles having rod shapes and round shapes under anoxic conditions

To explore the initial phase and morphology of the heterogeneously nucleated $\mathrm{Mn}$ (hydr)oxide on quartz substrate, the heterogeneous nucleation and growth of Mn (hydr)oxides were investigated in an anaerobic Coy chamber $\left(\mathrm{Po}_{\mathrm{O}}=0 \mathrm{~atm}\right)$ to inhibit any oxidation. $\mathrm{A} \mathrm{Mn}^{2+}(\mathrm{aq})$ concentration of $0.1 \mathrm{mM}$ and a $\mathrm{pH}$ of 10.1 were used under $1 \mathrm{mM}$ and $100 \mathrm{mM}$ IS conditions for $1 \mathrm{hr}$. To remove dissolved oxygen, we used DI water purged by $\mathrm{N}_{2}$ for 2 hrs. To quench further reaction and oxidation, the reacted quartz substrates were cleaned by $\mathrm{N}_{2}$-purged DI water in the anaerobic Coy chamber, and quickly dried using high purity nitrogen gas. Although the number concentration and size of nucleated primary particle were not same as in the samples prepared in the aerobic condition, from XPS analysis, the nucleated particles in the anaerobic condition suggest that $\mathrm{Mn}(\mathrm{OH})_{2}$ (s) is the initial phase of heterogeneously nucleated Mn (hydr)oxide nanoparticles (Figure S13). In addition, under anaerobic conditions, only big round particles formed by heterogeneous nucleation were observed on quartz, and not any rod-shaped particles. These round particles were identified as $\mathrm{Mn}(\mathrm{OH})_{2}(\mathrm{~s})$ using XPS. Under aerobic conditions, we observed both rod-shaped and round, aggregated particles (Figures 1A and C). XPS and XRD also shows the coexistence of $\mathrm{Mn}(\mathrm{OH})_{2}(\mathrm{~s})$ and $\mathrm{Mn}_{3} \mathrm{O}_{4}$ (Figure 3) under aerobic conditions. Although these results cannot give direct phase matching with the different shaped particles in AFM images, considering the Mn (hydr)oxide phase (from XPS) and morphology (from AFM) in anaerobic experiments, we can infer that the round particles are most likely $\mathrm{Mn}(\mathrm{OH})_{2}(\mathrm{~s})$ and the rod-shaped particles are $\mathrm{Mn}_{3} \mathrm{O}_{4}$. 

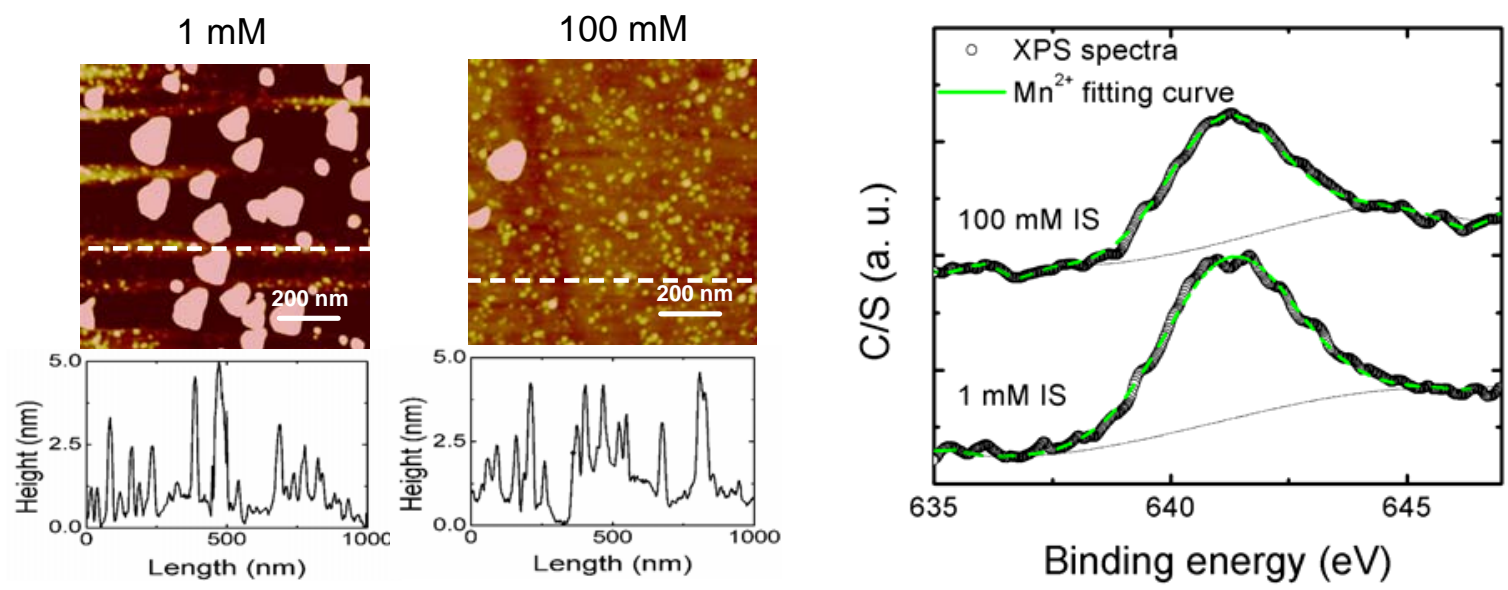

Figure S13. AFM height images and XPS spectra obtained in the anaerobic condition at $1 \mathrm{mM}$ IS and $100 \mathrm{mM}$ IS, compare the phase and morphology of heterogeneously nucleated particles on quartz with aerobic condition. XPS fitting results indicated that for both IS systems, the samples showed the Mn(II) oxidation status. The AFM image size is $1 \mu \mathrm{m} \times 1 \mu \mathrm{m}$. 
S19. Qualitative ratios of rod-shaped particles $\left(\mathrm{Mn}_{3} \mathrm{O}_{4}\right)$ to round particles $\left(\mathrm{Mn}(\mathrm{OH})_{2}(\mathrm{~s})\right)$ under $1 \mathrm{mM}$ IS and $100 \mathrm{mM}$ IS conditions.

The analysis of XPS spectra revealed that Mn(II) was the dominant oxidation state, at $60.8 \%$ and $73.0 \%$ in the $1 \mathrm{mM}$ IS and $100 \mathrm{mM}$ IS systems (Table S5), respectively. XPS provides information about the near surface of the sample. ${ }^{25}$ The height nanoparticles in our study is about 1-10 nm, which is in the near surface range for which XPS gives information, and the newly formed particles did not cover the entire substrate surface in all experimental system. In our XPS analyses, we obtained a strong signal from quartz that prevented further quantitative analysis of the contribution of hydroxide and oxide surface groups from the nanoparticle samples. If the XPS sampling size only encompasses part of the nanoparticles, this can cause errors in the determination of the dominant Mn oxidation state. However, we also got a strong signal from quartz, which is underneath the heterogeneously nucleated particles. This suggests that our XPS sampling includes the entire nanoparticle population. Thus, our discussion of predominance is valid. Thus, we conclude that $\mathrm{Mn}(\mathrm{OH})_{2}(\mathrm{~s})$ is the dominant $\mathrm{Mn}$ (hydr)oxide phase, while $\mathrm{Mn}_{3} \mathrm{O}_{4}$ also exists as an oxidized Mn (hydr)oxide phase in our experimental systems. Using Figure S14 (larger AFM scan size images than Figure 1 images), we can compare the relative quantities of round particles (containing only $\mathrm{Mn}(\mathrm{II})$ ) and rod-shaped particles (containing both $\mathrm{Mn}(\mathrm{II})$ and $\mathrm{Mn}(\mathrm{III})$ oxidation states) in $1 \mathrm{mM}$ IS and $100 \mathrm{mM}$ IS systems. We observed a higher ratio of round particles to rodshaped particles in the $100 \mathrm{mM}$ IS system, indicating that a slightly higher Mn(II) percentage can occur in $100 \mathrm{mM}$ IS system compared to $1 \mathrm{mM}$ IS system and confirming XPS measurements. 

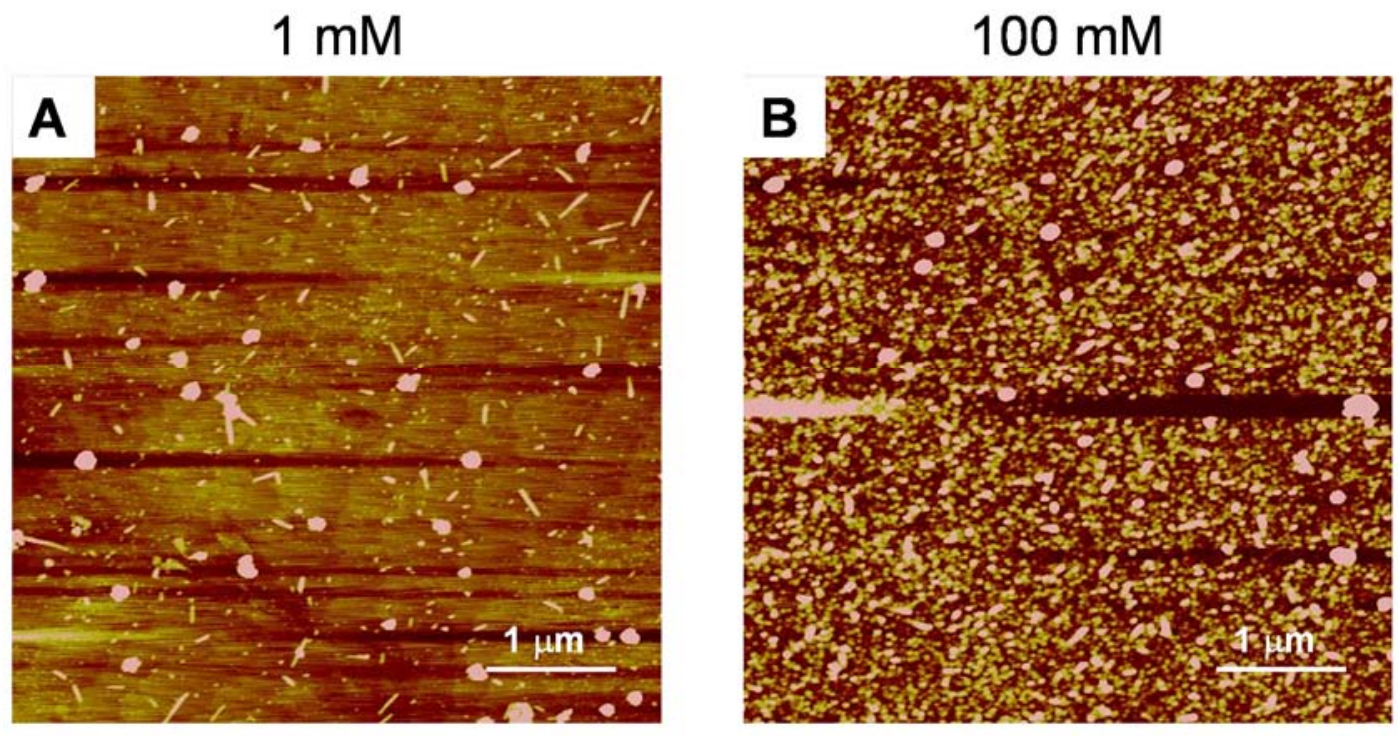

Figure S14. AFM height images for comparison of the ratio of rod-shaped particles $\left(\mathrm{Mn}_{3} \mathrm{O}_{4}\right)$ to round particles $\left(\mathrm{Mn}(\mathrm{OH})_{2}(\mathrm{~s})\right)$ between $1 \mathrm{mM}$ IS (A) and $100 \mathrm{mM}$ IS (B) systems. $1 \mathrm{mM}$ IS showed higher ratio of rod-shaped particles $\left(\mathrm{Mn}_{3} \mathrm{O}_{4}\right)$ to round particles $\left(\mathrm{Mn}(\mathrm{OH})_{2}(\mathrm{~s})\right)$ than $100 \mathrm{mM}$ IS. The AFM image size is $5 \mu \mathrm{m} \times 5 \mu \mathrm{m}$. 
S20. Aqueous $\mathrm{Mn}^{2+}$ observations to test supersaturation ratio changes induced by ionic strength.

The total particle volume of newly formed Mn (hydr)oxide in solution

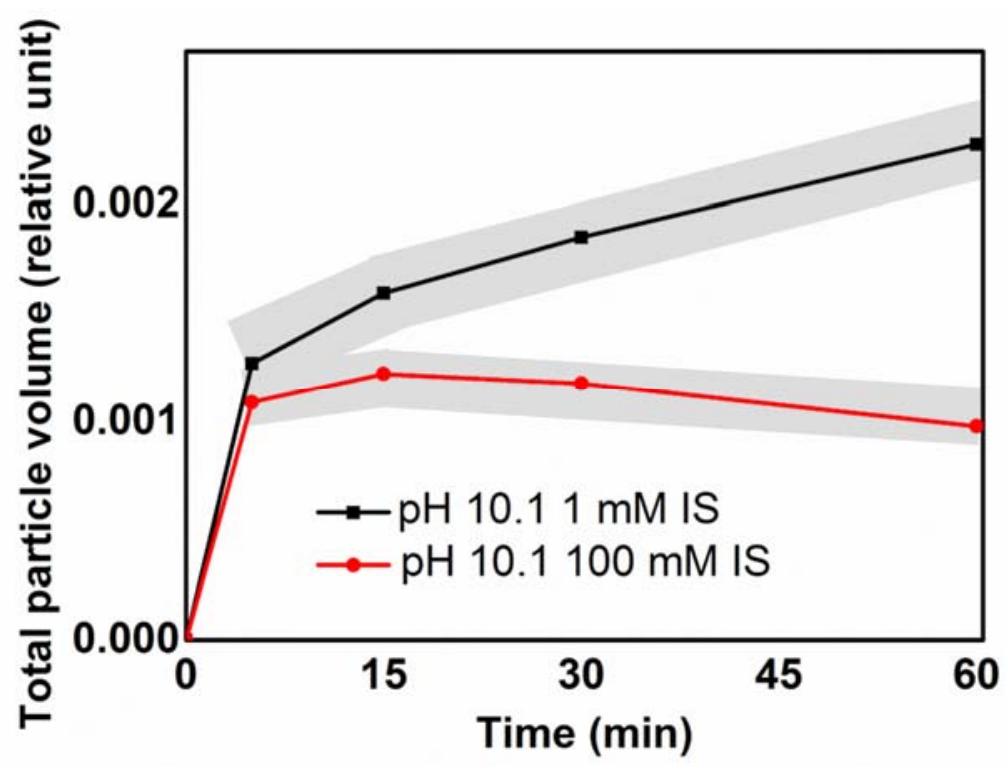

Figure S15. A comparison of total particle volume in solutions at varied IS suggests that homogeneous nucleation and growth are more dominant at $1 \mathrm{mM}$ IS than at $100 \mathrm{mM}$ IS. The grey bars represent the experimental error range for the calculation of total particle volume. 


\section{S21. Relative extent of Mn (hydr)oxide formation between homogeneous and heterogeneous nucleation.}

An approximate calculation was conducted to assess the relative extent of Mn (hydr)oxide formation between homogeneous and heterogeneous nucleation in the experimental system. From the ICP-OES measurement, after $1 \mathrm{hr}$ reaction, we found that about $70 \mu \mathrm{M}$ and $60 \mu \mathrm{M}$ of homogeneously nucleated particles were formed under $1 \mathrm{mM}$ and $100 \mathrm{mM}$ IS, respectively. The calculation below shows a relatively much less heterogeneous nucleation than homogeneous nucleation. As shown in Table S7, when we assumed that Mn (hydr)oxide $\left(\mathrm{Mn}(\mathrm{OH})_{2}(\mathrm{~s})\right)$ entirely covered the quartz substrate $(0.5 \mathrm{~cm} \times 0.5 \mathrm{~cm})$ with a $10 \mathrm{~nm}$ height, the concentration of heterogeneously nucleated Mn (hydr)oxide was $10 \mu \mathrm{M}, 7$ times smaller than the homogeneously nucleated Mn (hydr)oxide values obtained from ICP-OES. Although the calculated concentration of heterogeneously nucleated particle is an over-estimate value, given the observed AFM results, the calculation shows that homogeneous nucleation is much more dominant in the experimental systems. 
Table S1. Initial solution compositions for manganese (hydr)oxide precipitation experiments at initial $\mathrm{pH}$ of $10.1 \pm 0.1$.

\begin{tabular}{c|c|c|c}
\hline $\mathbf{M n}\left(\mathrm{NO}_{3}\right)_{2}(\mathbf{m M})$ & $\mathrm{NaNO}_{3}(\mathbf{m M})$ & $\mathrm{NaOH}(\mathbf{m M})$ & $\mathrm{IS}(\mathbf{m M})$ \\
\hline 0.1 & 1 & 0.15 & 1 \\
\hline 0.1 & 10 & 0.15 & 10 \\
\hline 0.1 & 100 & 0.15 & 100 \\
\hline
\end{tabular}


Table S2. Thermodynamically calculated -bicarbonate and -carbonate concentrations.

\begin{tabular}{c|c|c}
\hline & $1 \mathrm{mM}$ IS system $(\mathrm{mM})$ & $100 \mathrm{mM}$ IS system $(\mathrm{mM})$ \\
\hline $\mathrm{MnHCO}_{3}{ }^{+}$ & $2.304 \mathrm{e}-004$ & $9.667 \mathrm{e}-005$ \\
\hline $\mathrm{MnCO}_{3}(\mathrm{aq})$ & $4.285 \mathrm{e}-005$ & $1.106 \mathrm{e}-005$ \\
\hline $\mathrm{Mn}^{2+}$ & $9.930 \mathrm{e}-002$ & $9.312 \mathrm{e}-002$ \\
\hline
\end{tabular}


Table S3. Summary of XPS fitting references of Mn(II) and Mn(III).

\begin{tabular}{|c|c|c|c|c|}
\hline $\begin{array}{l}\text { Oxidation } \\
\text { state }\end{array}$ & Mn oxide & $\begin{array}{l}\text { Mn 2p } p_{3 / 2} \text { Binding } \\
\text { energy }(e V)\end{array}$ & $\Delta E_{\mathrm{Mn} 3 \mathrm{~s}}$ & References \\
\hline \multirow{7}{*}{$\operatorname{Mn}(\mathrm{II})$} & $\mathrm{MnO}$ & 640.8 & 5.8 & Junta and Hochella (1994) ${ }^{26}$ \\
\hline & $\mathrm{MnO}$ & 641.0 & 6.1 & $\begin{array}{l}\text { Di Castro and Polzonetti } \\
(1989)^{27}\end{array}$ \\
\hline & $\mathrm{MnO}$ & 641.2 & & Ramesh et. al. $(2008)^{28}$ \\
\hline & $\mathrm{MnO}$ & & 6.0 & Gorlin and Jaramillo $(2010)^{29}$ \\
\hline & $\mathrm{MnO}$ & 641.2 & & Liu et. al. (2014) \\
\hline & $\mathrm{MnO}$ & & 5.7 & Cerrato et. al. $(2010)^{31}$ \\
\hline & $\begin{array}{l}\mathrm{Mn}(\mathrm{OH})_{2} \\
(\mathrm{~s})\end{array}$ & 641.0 & 5.7 & This work \\
\hline \multirow{7}{*}{$\operatorname{Mn}(\mathrm{III})$} & $\mathrm{Mn}_{2} \mathrm{O}_{3}$ & 641.9 & 5.2 & $\begin{array}{l}\text { Di Castro and Polzonetti } \\
(1989)^{27}\end{array}$ \\
\hline & $\mathrm{Mn}_{2} \mathrm{O}_{3}$ & 641.8 & 5.0 & Ramesh et. al. $(2008)^{28}$ \\
\hline & $\mathrm{Mn}_{2} \mathrm{O}_{3}$ & 641.8 & & Kuezma et. al. $(2012)^{32}$ \\
\hline & $\mathrm{Mn}_{2} \mathrm{O}_{3}$ & & 5.2 & Cerrato et. al. $(2010)^{31}$ \\
\hline & $\mathrm{Mn}_{2} \mathrm{O}_{3}$ & & 5.1 & Gorlin and Jaramillo $(2010)^{29}$ \\
\hline & $\gamma-\mathrm{MnOOH}$ & 641.7 & 5.4 & Junta and Hochella (1994) ${ }^{26}$ \\
\hline & $\gamma-\mathrm{MnOOH}$ & 641.7 & 5.4 & This work \\
\hline \multirow{4}{*}{$\mathrm{Mn}(\mathrm{II} / \mathrm{III})$} & $\mathrm{Mn}_{3} \mathrm{O}_{4}$ & & 5.3 & Matsumoto and Sato $(1986)^{33}$ \\
\hline & $\mathrm{Mn}_{3} \mathrm{O}_{4}$ & 641.4 & 5.5 & Ardizzone et. al. $(1998)^{34}$ \\
\hline & $\mathrm{Mn}_{3} \mathrm{O}_{4}$ & 641.4 & 5.3 & Oku et. al. $(1975)^{35}$ \\
\hline & $\mathrm{Mn}_{3} \mathrm{O}_{4}$ & 641.5 & 5.3 & $\begin{array}{l}\text { Di Castro and Polzonetti } \\
\qquad(1989)^{27}\end{array}$ \\
\hline
\end{tabular}


Table S4. Zeta potential values of quartz powder and heterogeneously nucleated Mn (hydr)oxides on quartz powder surfaces.

\begin{tabular}{|c|c|c|c|c|}
\hline $\begin{array}{c}\text { IS } \\
(\mathrm{mM})\end{array}$ & $\begin{array}{c}\text { Quartz } \\
\text { (mV) }\end{array}$ & $\begin{array}{l}\text { Homogeneously } \\
\text { produced Mn } \\
\text { (hydr)oxide particles } \\
\text { without quartz } \\
\text { (mV) }\end{array}$ & $\begin{array}{l}\text { Quartz with reaction } \\
\text { of } \mathrm{Mn} \text { at } 0 \mathrm{~min} \\
(\mathrm{mV})\end{array}$ & $\begin{array}{c}\text { Quartz with reaction } \\
\text { of } \mathrm{Mn} \text { at } 60 \mathrm{~min} \\
(\mathrm{mV})\end{array}$ \\
\hline 1 & $-38.8 \pm 2.2$ & $1.4 \pm 0.4$ & $-40.7 \pm 1.3$ & $-37.9 \pm 1.3$ \\
\hline 10 & $-40.1 \pm 2.6$ & $-0.5 \pm 2.2$ & $-39.5 \pm 3.6$ & $-31.6 \pm 5.2$ \\
\hline 100 & $-14.8 \pm 0.4$ & $6.2 \pm 2.0$ & $-15.7 \pm 1.1$ & $-12.2 \pm 1.5$ \\
\hline
\end{tabular}


Table S5. Relative area of XPS spectra obtained from the integration of Gaussian-Lorentzian curve-fitting. $\mathrm{Mn}^{2+}$ and $\mathrm{Mn}^{3+}$ are fitted at binding energies of $641.1 \mathrm{eV}$ and $641.8 \mathrm{eV}$, respectively.

\begin{tabular}{c|c|c}
\hline & $\mathbf{M n}^{2+}$ (FWHM) & $\mathbf{M n}^{3+}$ (FWHM) \\
\hline 1 mM IS & $60.8 \%(2.76)$ & $39.2 \%(3.50)$ \\
\hline $100 \mathrm{mM}$ IS & $73.0 \%(2.97)$ & $27.0 \%(3.82)$ \\
\hline
\end{tabular}


Table S6. Calculation of supersaturation of $\mathrm{Mn}(\mathrm{OH})_{2}$ (s) under varied IS conditions using GWB 8.0 .

\begin{tabular}{c|c|c|c|c|c}
\hline & $\mathrm{Mn}^{2+}(\mathrm{mM})$ & Activity & $\mathrm{H}^{+}$ & Activity & Supersaturation ratio \\
\hline $1 \mathrm{mM}$ & 0.1 & 0.8471 & $10^{-10.1}$ & 0.9583 & 9.22 \\
\hline $100 \mathrm{mM}$ & 0.1 & 0.4043 & $10^{-10.1}$ & 0.7688 & 6.84 \\
\hline
\end{tabular}


Table S7. Rough calculations of heterogeneously nucleated Mn (hydr)oxide on quartz substrate, showing a relatively much smaller amount of heterogeneously nucleated Mn (hydr)oxide than homogeneously nucleated Mn (hydr)oxide.

\begin{tabular}{c|c}
\hline \multicolumn{1}{c|}{ Surface area of the quartz substrate $\left(\mathrm{m}^{2}\right)$} & $2.5 \mathrm{e}-5$ \\
\hline Particle height $(\mathrm{m})$ & $1 \mathrm{e}-8$ \\
\hline Volume of the Mn (hydr)oxide covering quartz surface & $2.5 \mathrm{e}-13$ \\
\hline Density of $\mathrm{Mn}(\mathrm{OH}) 2(\mathrm{~s})\left(\mathrm{g} / \mathrm{cm}^{3}\right)$ & 3.27 \\
\hline Mass of the Mn (hydr)oxide covering quartz surface $(\mathrm{g})$ & $8.2 \mathrm{e}-7$ \\
\hline Mole of the Mn (hydr)oxide covering quartz surface & $9.2 \mathrm{e}-9$ \\
$(\mathrm{~mol})$ & 10 \\
\hline Molar concentration in $1 \mathrm{ml}$ reaction solution $(\mu \mathrm{M})$ & \\
\hline
\end{tabular}




\section{References}

1. Jun, Y.-S.; Lee, B.; Waychunas, G. A., In situ observations of nanoparticle early development kinetics at mineral-water interfaces. Environ. Sci. Technol. 2010, 44, (21), 8182-8189.

2. Hu, Y.; Lee, B.; Bell, C.; Jun, Y.-S., Environmentally abundant anions influence the nucleation, growth, ostwald ripening, and aggregation of hydrous Fe (III) oxides. Langmuir 2012, 28, (20), 7737-7746.

3. Hu, Y.; Neil, C.; Lee, B.; Jun, Y.-S., Control of heterogeneous Fe (III)(hydr) oxide nucleation and growth by interfacial energies and local saturations. Environ. Sci. Technol. 2013, 47, (16), 9198-9206.

4. Li, Q.; Fernandez-Martinez, A.; Lee, B.; Waychunas, G. A.; Jun, Y.-S., Interfacial Energies for Heterogeneous Nucleation of Calcium Carbonate on Mica and Quartz. Environ. Sci. Technol. 2014, 48, (10), 5745-5753.

5. Duckworth, O. W.; Sposito, G., Siderophore-manganese (III) interactions. I. Air-oxidation of manganese (II) promoted by desferrioxamine B. Environ. Sci. Technol. 2005, 39, (16), 60376044.

6. Duckworth, O. W.; Sposito, G., Siderophore-manganese (III) interactions II. Manganite dissolution promoted by desferrioxamine B. Environ. Sci. Technol. 2005, 39, (16), 6045-6051.

7. Churchill, H.; Teng, H.; Hazen, R. M., Correlation of pH-dependent surface interaction forces to amino acid adsorption: Implications for the origin of life. Am. Mineral. 2004, 89, (7), 10481055.

8. Liu, X., Generic progressive heterogeneous processes in nucleation. Langmuir 2000, 16, (18), 7337-7345.

9. Liu, X. Y.; Sawant, P. D., Micro/Nanoengineering of the Self-Organized Three-Dimensional Fibrous Structure of Functional Materials. Angew. Chem. 2002, 114, (19), 3793-3797.

10. Du, N.; Liu, X. Y.; Hew, C. L., Ice nucleation inhibition mechanism of antifreeze by antifreeze protein. J. Biol. Chem. 2003, 278, (38), 36000-36004.

11. Fletcher, N., Size effect in heterogeneous nucleation. J. Chem. Phys. 1958, 29, (3), 572-576.

12. Morgan, J. J., Kinetics of reaction between $\mathrm{O}_{2}$ and $\mathrm{Mn}$ (II) species in aqueous solutions. Geochim. Cosmochim. Acta 2005, 69, (1), 35-48.

13. Morgan, J. J. Chemistry of Aqueous Manganese II and IV: A Thesis. Harvard University, 1964.

14. Luther, G., The frontier-molecular-orbital theory approach in geochemical processes. 1990.

15. Hem, J. D., Rates of manganese oxidation in aqueous systems. Geochim. Cosmochim. Acta 1981, 45, (8), 1369-1374.

16. Hem, J. D.; Lind, C. J., Nonequilibrium models for predicting forms of precipitated manganese oxides. Geochim. Cosmochim. Acta 1983, 47, (11), 2037-2046.

17. Fox, R. K.; Swinehart, D. F.; Garrett, A., The equilibria of manganese hydroxide, $\mathrm{Mn}(\mathrm{OH})_{2}$, in solutions of hydrochloric acid and sodium hydroxide. J. Am. Chem. Soc. 1941, 63, (7), 17791782.

18. Birkner, N.; Navrotsky, A., Thermodynamics of manganese oxides: Effects of particle size and hydration on oxidation-reduction equilibria among hausmannite, bixbyite, and pyrolusite. Am. Mineral. 2012, 97, (8-9), 1291-1298.

19. de Leeuw, N. H.; Cooper, T. G., Surface simulation studies of the hydration of white rust $\mathrm{Fe}(\mathrm{OH})_{2}$, goethite $\alpha-\mathrm{FeO}(\mathrm{OH})$ and hematite $\alpha-\mathrm{Fe}_{2} \mathrm{O}_{3}$. Geochim. Cosmochim. Acta 2007, 71, (7), 1655-1673.

20. Navrotsky, A.; Ma, C.; Lilova, K.; Birkner, N., Nanophase transition metal oxides show large 
thermodynamically driven shifts in oxidation-reduction equilibria. Science 2010, 330, (6001), 199-201.

21. Duval, Y.; Mielczarski, J.; Pokrovsky, O.; Mielczarski, E.; Ehrhardt, J., Evidence of the existence of three types of species at the quartz-aqueous solution interface at pH 0-10: XPS surface group quantification and surface complexation modeling. J. Phys. Chem. B 2002, 106, (11), 2937-2945.

22. Tang, C.; Zhu, J.; Zhou, Q.; Wei, J.; Zhu, R.; He, H., Surface Heterogeneity of $\mathrm{SiO}_{2}$ Polymorphs: An XPS Investigation of $\alpha$-Quartz and $\alpha$-Cristobalite. J. Phys. Chem. C 2014, $118,(45), 26249-26257$.

23. Nesbitt, H.; Banerjee, D., Interpretation of XPS Mn (2p) spectra of Mn oxyhydroxides and constraints on the mechanism of MnO2 precipitation. Am. Mineral. 1998, 83, (3), 305-315.

24. Yang, Y.; Zhang, S.; Wang, S.; Zhang, K.; Wang, H.; Huang, J.; Deng, S.; Wang, B.; Wang, Y.; Yu, G., Ball milling synthesized MnOx as highly active catalyst for gaseous POPs removal: significance of mechanochemically induced oxygen vacancies. Environ. Sci. Technol. 2015, 49, (7), 4473-4480.

25. Tang, C. Y.; Kwon, Y.-N.; Leckie, J. O., Probing the nano- and micro-scales of reverse osmosis membranes - A comprehensive characterization of physiochemical properties of uncoated and coated membranes by XPS, TEM, ATR-FTIR, and streaming potential measurements. $J$. Membrane Sci. 2007, 287, (1), 146-156.

26. Junta, J. L.; Hochella Jr, M. F., Manganese (II) oxidation at mineral surfaces: A microscopic and spectroscopic study. Geochim. Cosmochim. Acta 1994, 58, (22), 4985-4999.

27. Di Castro, V.; Polzonetti, G., XPS study of MnO oxidation. J. Electron Spectrosc. Relat. Phenom. 1989, 48, (1), 117-123.

28. Ramesh, K.; Chen, L.; Chen, F.; Liu, Y.; Wang, Z.; Han, Y.-F., Re-investigating the CO oxidation mechanism over unsupported $\mathrm{MnO}, \mathrm{Mn}_{2} \mathrm{O}_{3}$ and $\mathrm{MnO}_{2}$ catalysts. Catal. Today 2008, $131,(1), 477-482$.

29. Gorlin, Y.; Jaramillo, T. F., A Bifunctional Nonprecious Metal Catalyst for Oxygen Reduction and Water Oxidation. J. Am. Chem. Soc. 2010, 132, (39), 13612-13614.

30. Liu, B.; Hu, X.; Xu, H.; Luo, W.; Sun, Y.; Huang, Y., Encapsulation of MnO Nanocrystals in Electrospun Carbon Nanofibers as High-Performance Anode Materials for Lithium-Ion Batteries. Sci. Rep. 2014, 4.

31. Cerrato, J. M.; Hochella Jr, M. F.; Knocke, W. R.; Dietrich, A. M.; Cromer, T. F., Use of XPS to identify the oxidation state of $\mathrm{Mn}$ in solid surfaces of filtration media oxide samples from drinking water treatment plants. Environ. Sci. Technol. 2010, 44, (15), 5881-5886.

32. Kuezma, M.; Devaraj, S.; Balaya, P., $\mathrm{Li}_{2} \mathrm{MnSiO}_{4}$ obtained by microwave assisted solvothermal method: electrochemical and surface studies. J. Mater. Chem. 2012, 22, (39), 21279-21284.

33. Matsumoto, Y.; Sato, E., Electrocatalytic properties of transition metal oxides for oxygen evolution reaction. Mater. Chem. Phys. 1986, 14, (5), 397-426.

34. Ardizzone, S.; Bianchi, C. L.; Tirelli, D., $\mathrm{Mn}_{3} \mathrm{O}_{4}$ and $\gamma$-MnOOH powders, preparation, phase composition and XPS characterisation. Colloids Surf. A Physicochem. Eng. Asp. 1998, 134, (3), 305-312.

35. Oku, M.; Hirokawa, K.; Ikeda, S., X-ray photoelectron spectroscopy of manganese-oxygen systems. J. Electron Spectrosc. Relat. Phenom. 1975, 7, (5), 465-473. 